\title{
The Future of the Alternatives Energies: A Forecast based on Technological Forecasting Techniques
}

\author{
João Carlos de Oliveira Matias ${ }^{1}$ and Tessaleno Campos Devezas ${ }^{1}$ \\ ${ }^{1}$ Department of Electromechanical Engineering \\ University of Beira Interior \\ P - 6201-001 Covilhã (Portugal) \\ phone:+351 275 329947, fax:+351 275 329972, e-mail: matias@demnet.ubi.pt, tessalen@demnet.ubi.pt
}

\begin{abstract}
Bearing in mind the dynamics associated with long structural waves, and making use of technological forecasting tools, a logistic substitution and a Delphi technique, three scenarios are built and analysed: an exploratory one (logistic substitution), a Delphi-based one, and another one resulting from the combination of the two previous ones. In general terms, the indications of the Delphi survey confirm the dynamics of the logistic substitution, even if considering different time spans. Thus, it can be concluded that a substitution of the "non-solid hydrocarbons" for the alternative energies sources will happen in the future. Our study points out to the leadership of the alternative energies as the main primary energy by $2050-2070$. In other words we can say that a new techno-economic paradigm, based on a more sustainable energy regime, will still burgeon in the present century. In this new energy regime the renewable energies will play an essential role, being able to assume the leadership as the main primary energy source. However, in the path toward this future, the role of the State will remain fundamental, but in present and near future it will be mainly related to the question of defence in the struggle against energy dependence.
\end{abstract}

\section{Key words}

Dynamics of Consumption, Technological Transformations, Global Energy Shifts, Sustainable Energy Regime, "Resources Wars".

\section{Introduction}

Figure 1 presents the evolution of the primary energy sources market share. It is convenient to enhance two great transitions that were responsible for the structural transformations occurred in the energetic systems. First, the steam engine (associated to coal) and, secondly, the increase of the diversification of the final use technologies and the energy sources diversification. The first transition is related with the first and second technological transformations, while the second transition is, even if not exclusively, linked with the third and fourth technological transformations, standing out the electricity as means of energy transportation and internal combustion engine associate to oil.
Figure 1 also shows some points that must be enhanced. From these there can be stood out the following ones:

$>$ The long and gradual substitution among the primary energy sources, such as the substitution of wood (traditional renewable fuel) for fossil fuels;

$>$ The domain of coal during a long period of time, reaching more than two thirds of the consumed primary energy;

$>$ The almost simultaneous introduction of oil and natural gas, this last firstly as a product resultant of the oil production and later as a primary energy source;

$>$ The peak of oil consumption in the seventies, coincident with the oil crisis;

$>$ Finally, some turbulence in the consumption dynamics of the primary energy sources during the last two decades.

In technological terms, it was during the last 250 years that happened five major technological transformations [2],[3]. The first transformation (1770-1800) was linked with the substitution of wood for coal as primary energy source, with consequences in iron-making, in fuelling the first steam engine, in building the first canals and in mechanizing cotton spinning. The second transformation (1830-1850) was related to the use of the steam power to the textile industry and to transportation (railways and steam boat). This transformation, along with the first one, is associated to the " 1 st Industrial Revolution". The third transformation (1860-1900) was a complex one: it centered itself on steel-making and on the mechanization of manufacturing, on illumination, telephones, electrification and on the internal combustion engines. It was also characterized by the beginning of the substitution of coal by oil as primary energy source, being called the " 2 nd Industrial Revolution". The fourth transformation (19301950) was centered on synthetic materials and electronics. Finally, the fifth one, beginning around 1980, centers itself on the convergence of computers and telecommunications. This is to say, the first three had a greater influence on industry, being nicknamed as "industrial revolutions". On its turn, the fourth transformation had larger impact on the 
consumer, given the great amount of new products. The fifth one will influence as much the industry as the consumer, due to the emergence of new products and industrial technologies (also new industries) that will lead this wave.

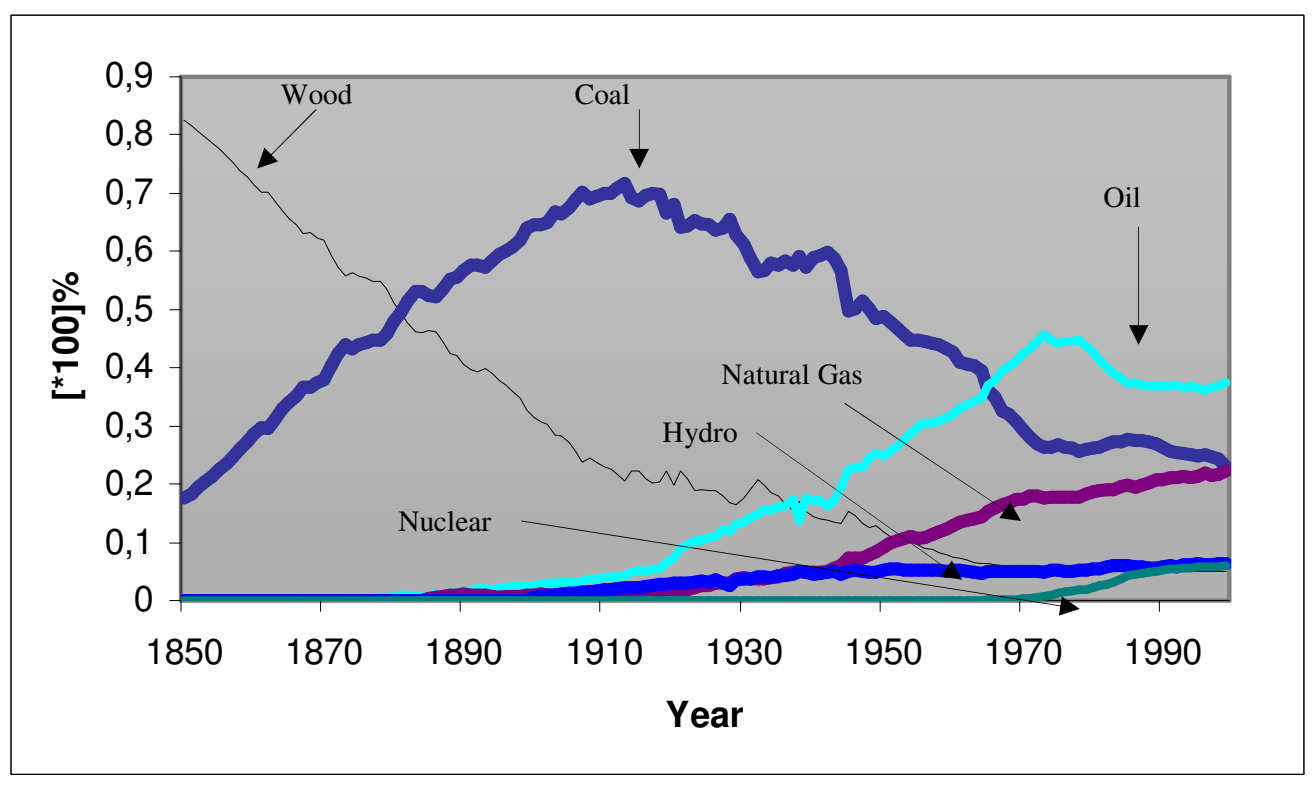

Fig. 1. Market share of primary energy sources evolution (1860-2000)

Bearing in mind these data, there are no doubts that the primary energy sources are associated to the major technological transformations and consequently associated to the structural long waves (frequently known as Kondratieff Waves or simply K-waves). Coal began to substitute wood in the eighteenth century $\left(1^{\text {st }}\right.$ technological transformation, responsible for the economic expansion of the $1^{\text {st }} \mathrm{K}$-wave), being diffused in the nineteenth century (it surpassed wood in the peak of the $2^{\text {nd }} \mathrm{K}$-wave), reaching the stagnation (beginning of the decline) in the twentieth century (it reached the maximum point in the peak of the $3^{\text {rd }} \mathrm{K}$-wave). During the period from 1800 to 1920 , coal went from providing around $10 \%$ to over $60 \%$ of the word's total commercial energy requirements, being linked to the iron and steel industries, being the primary energy source of the first and second technological transformations. On its turn, the non-solid fossils (FNS - oil and natural gas) began to substitute coal in the nineteenth century $\left(3^{\text {rd }}\right.$ technological transformation, responsible for the economic expansion of the $3^{\text {rd }} \mathrm{K}$-wave), being diffused in the twentieth century (they surpassed coal in the peak of the $4^{\text {th }} \mathrm{K}$-wave), being foreseen the reach of stagnation in the present century (the maximum point (turning point) in the peak the $5^{\text {th }} \mathrm{K}$-wave). During the period from 1920 to 1973, the oil market share grew from $10 \%$ to around $50 \%$, being mainly linked to the automobile industry, being the primary energy source to the $3^{\text {rd }}$ and $4^{\text {th }}$ technological transformations. Notice that this last phase was less intensive in natural resources than the previous ones. Thus, even if in global terms the energy consumption continues to grow, the energy intensity will continue to decrease, in spite of the increase in the development countries, at least in commercial energy terms.
On the other hand, in spite of the increase of carbon emissions to the atmosphere in consequence of the fuels fossil consumption, the amount of carbon emitted by consumed energy unit (carbonic intensity, tC/toe) is decreasing. This is not more than the reflex of the primary energy sources substitution along the last two centuries. First, the substitution of wood $(1,25 \mathrm{tC} /$ toe $)$ for coal $(1,08$ $\mathrm{tC} /$ toe $)$, and this last one for FNS [oil $(0,84 \mathrm{tC} /$ toe $)$ and, lately, natural gas $(0,64 \mathrm{tC} /$ toe $)]$.

Bearing in mind what was just referred, there are evidences that in the past there has been an interaction between three dynamic systems: Geopolitical Rivalry, Commercial Competition and Social Unrest, where one of the key issues was the state intervention, in a military perspective and geopolitical rivalry, resulting in two different regimes domain [4]. The first one linked to coal and its technologies and the second one linked to oil and its technologies, in spite of the fact that natural gas cannot be despised. It was evident the rivalry among industrialized nations toward a military and economic supremacy as one of the most important characteristics of the long waves. This rivalry has periodically driven an advanced industrial states direct intervention in the domestic and foreign energy industries, because at the military and industrial level, they are dependent of a certain primary energy source. This point of view is coherent with data of the past, where the British State was the first to promote the coal production, given the increase of the meaning of the iron, railways, among other, in economic and military issues. The "leadership" of coal coincided with the British hegemony, where the state supported and promoted the private investment that led to 
the consolidation of coal at the beginnings of the twentieth century.

Later, by the early twentieth century, political, commercial and social dynamics began the change in favor of oil "against" coal, to an oil-based regime (FNS, considering the natural gas). In fact, the beginning of the oil-based industries is marked around 1890s, when escalating military rivalry led to "arms race" between most advanced nations. Under pressure, they accelerated the technological innovations in the naval sectors, being forced the shifting from coal to oil-based propulsion systems. Thus, in the beginning of the World War I, most navies were in process of conversion to oil. On the other hand, in both World Wars, advanced countries invested on production of oil-powered trucks and airplanes. The mass production of oil-powered ships, vehicles and aircrafts during each World War had an important role in setting the stage for post-war commercial booms in new leading sector industries.

It is noticed, this way, the role of geopolitical dynamics in the transition from wood to coal and from coal to oil (FNS). It becomes notable the case of the British hegemony in the coal-based regime, while the expansion of oil led to the geopolitical and economic power of the USA, in the postWorld War II period, since the $3^{\text {rd }}$ technological transformation was a transition period. In post-World War II period (around twenty five years), the USA dominated in technological terms, having happened there the most important technical progresses. In that period, the technological politics and science and technology investments supported the several researches, mainly of national and space defense interest, facing the "Cold War" against East, principally, against the already extinguished Soviet Union. And in future, how will it be?

Bearing in mind the earlier energy shifts and the important role of geopolitical, commercial and social dynamics in past, probably in future the conventional energy systems will shift in favor of an alternative-based regime, in which the renewable energies and the nuclear energy are included (the short/medium term just the fission). In order to understand the potential for the relative world-rapid diffusion of these new energy technology it is important to understand the long wave dynamics, having associated regime shifts in the past. Social behaviors changes can lead to a renewable-based regime. But, will they be convergent with geopolitical and commercial interests?

\section{Future Perspectives}

Making use of two of technological forecast tools, namely the logistics curve (quantitative technique) and the Delphi technique (qualitative and judgmental technique), three long-term scenarios [1] were built: an exploratory one, using the substitution logistics (determinists), an Delphi-based indicative one, and another one resulting from combination of the two previous one (hybrid scenario). Notice that, and bearing in mind some presuppositions related with the technologies diffusion time, oil and natural gas are grouped (FNS) in logistic substitution, as like as alternative totality energies (renewable energies without traditional wood and nuclear energy).

For the Delphi-based scenario were selected 180 international energy experts. In $1^{\text {st }}$ round answered 78 panelists, and in the end of the $3^{\text {rd }}$ round the final panel was summarized to 68 experts (50\% of Western Europe, $16 \%$ of North America, $13 \%$ of Asia and Oceania, 12\% of South America, $6 \%$ of Eastern Europe and 3\% of Africa).

This work presents only the combined scenario, due to the incorporation of a complementarity between two different techniques. However, notice that one of the reasons for the Delphi technique use (group judgmental technique) was to verify if it is possible to represent the energy systems behavior trough logistic substitution among primary energy sources. In the comparison between exploratory scenario and Delphi-based one it is verified a change dynamics convergence, but there isn't a convergence of "occurrence timing". In other words, the indications of the Delphi survey confirm the dynamics of the logistic substitution, even if considering different time spans, despite of the fact the differences are not very significant [1]. Thus, the hybrid scenario goal is to use the information integration of several sources on different ways in a simple presentation, being grouped the extrapolations results and experts' appreciation. In this way, it was built a scenario that uses a combination between the logistic substitution and the Delphi-based indications. Unlike what it was done for the exploratory scenario (deterministic), there were not chosen identification periods (reference periods for forecasting) for the best data fitting. For each primary energy source, or energy sources groups, it was considered the identification period, which represents the dynamics substitution future, bearing in mind Delphi-based orientations, as well as other kind of indications. Figure 2 shows the substitution between primary energy sources, while Table I presents the market share forecasting for the next decades.

However, and in spite of only being explicitly presented the hybrid scenario, through the three scenarios it is possible to point out the following indications [1]:

- Wood will have its "dusk" (market share $\leq$ $1 \%$ ), as traditional energy, by 2010-2015;

- Coal will have its "dusk" between 2040 and

2060

- Among the FNS, natural gas can surpass oil by 2040-2050, but it will be difficultly assumed as main primary energy, if the alternative energies are considered in the totality, being assumed as a FNS "up-grade", being assumed as a transition fuel;

- FNS can stay in the leadership up until 20502070, moment in which they will be surpassed by the group of the alternative energies;

- Nuclear fission will remain as a source of energy, even having the possibility to increase its market share, being very important for the consolidation of the alternative energies, even if not in short terms; 
- Nuclear fusion, as commercial energy, will be difficultly available before 2050-2060;
- In short terms, the most effective way to reduce the greenhouse effect is to improve the fossil fuels combustion efficiency.

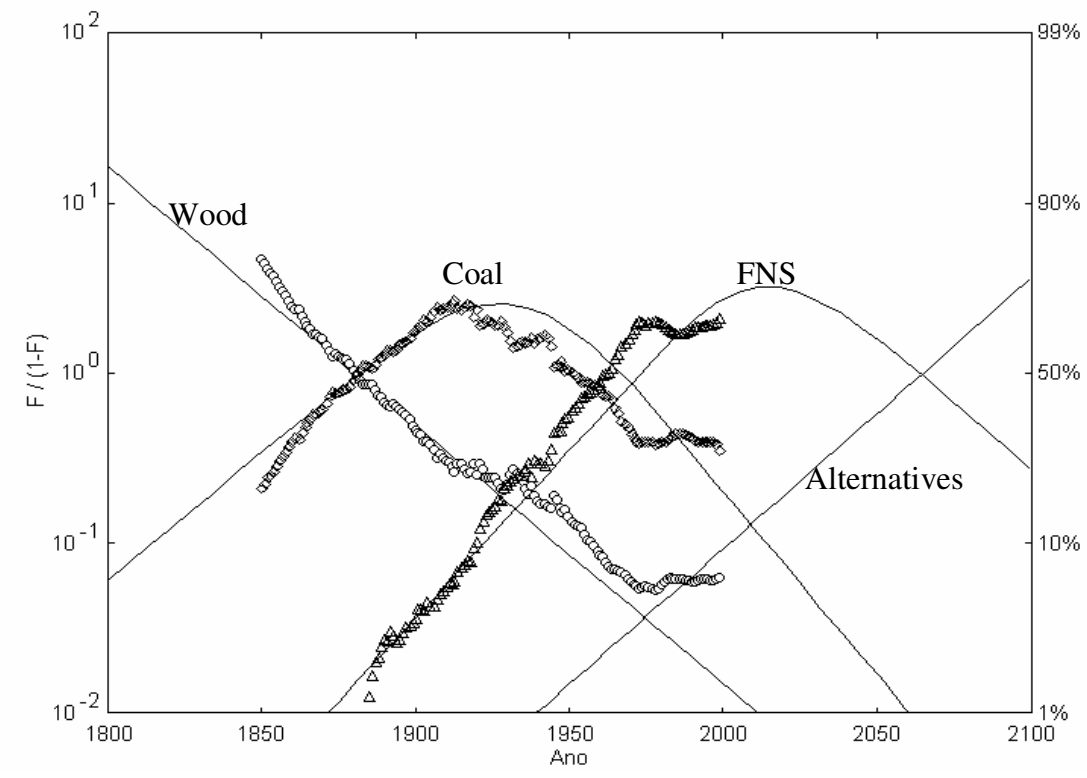

Fig. 2. Logistic substitution between primary energy sources $(1860-1999)$ and the market share forecasting for hybrid scenario [1]

TABLE I - Market share forecasting for hybrid scenario [1]

\begin{tabular}{|l|c|c|c|c|c|c|c|}
\hline \multicolumn{1}{|c|}{$\begin{array}{c}\text { Year } \\
\text { Source } \\
\downarrow\end{array}$} & 2025 & 2040 & 2045 & 2050 & 2065 & 2075 & 2100 \\
\hline Wood & $<1 \%$ & $<1 \%$ & $<1 \%$ & $<1 \%$ & $<1 \%$ & $<1 \%$ & $<1 \%$ \\
\hline Coal & $6 \%$ & $3 \%$ & $2,5 \%$ & $2 \%$ & $<1 \%$ & $<1 \%$ & $<1 \%$ \\
\hline FNS & $75 \%$ & $68 \%$ & $64,5 \%$ & $61 \%$ & $50 \%$ & $41 \%$ & $22 \%$ \\
\hline Alternatives & $19 \%$ & $29 \%$ & $33 \%$ & $37 \%$ & $50 \%$ & $59 \%$ & $78 \%$ \\
\hline
\end{tabular}

\section{Final Considerations}

The substitution for the alternative energies can be slower in case of smaller state intervention than it was in the past. By that time, we will have a key point: on one side, it may exist a less geopolitical interest by state investment in the alternatives, unlike what happened with the British hegemony (coal) and American hegemony (oil). This may not motivate the private investment, due to the great "payback-time" of the alternatives, which have a great initial investment, unlike nowadays fossil fuels. But, on the other hand, it may exist a great bet on alternative energies, due to the need of the resources antidependence.

In a "market economy", the competition is very strong, and as the companies have to satisfy their shareholders, they opt for activities with reduced paybacks. Like this, the energy market liberalization is dangerous for the alternative energies, being doubtful its future [5],[6]. But the State, on one way or on another, will have to be, just like in the past during the rise of coal and oil and nowadays with the natural gas, the main instigator of the alternative energies. This due to the environmental problems associated to the energy use, besides the elimination of external dependences and the energy technologies importance in the economy. The state support will be the equilibrium point in a liberalized market, guiding and stimulating the investors, even in terms of investments in I\&D. So, private investors by itself won't bet on innovation in alternative technologies. On the other hand, they will have to apply rates and tariffs, due to the externalities associated to each energy source. The current conditions are not attractive for the investors, given the high capitals and long construction periods with returns, if not doubtful, at least slowers. But 
the alternative energies will be an essential factor, besides the combat to the emissions of fossil fuels combustion, in a combat politic to the insecurity of the energy markets, nowadays oil-dependent.

Thus, and bearing mind the nuclear fears, as well as financial factors, the renewable energies group will have an essential role in the two coming structural waves. In this wave $\left(5^{\text {th }}\right)$, on an innovative structural form, and, in the following one, in a structural form of consolidation [7], the alternative energies can reach the leadership as the main primary energy sources during the second half of this century. But, for that, the state intervention will be fundamental, because in the past none of the substitutions were stimulated by the resources depletion, but by technological and social needs, which lead to great structural changes, from which it cannot be dissociated environmental factors. Like this, for the continuity of the substitution process there should be more important economic, geopolitical, environmental and social issues than resources depletion.

Now, we cannot be waiting for the FNS depletion to proceed to the substitution for the renewable energies, because this is going to take place by the end of this century. This paper presents a new way of looking into the future of primary energy sources. A proper substitution dynamics amongst the primary energy sources was demonstrated using an innovative combination between a quantitative technique (logistic substitution), insensible to outward influences, with a judgmental technique (Delphi), capable of forecasting tendencies. Bearing in mind this dynamics it is possible to point out a progressive substitution of the non-solid fossil fuels by the alternative energies.

For the coal-based regime, oil-based regime and, in a certain way, in the beginning of nuclear investigation, there was present geopolitical and world hegemony. On its turn, in the case of the renewable energies, and remaining alternatives, it will be for a question of defense of "external non-dependence", when at this moment most of the FNS reserves are in Middle East and Caspian Sea. In this context, during the last years the USA has been having a military and economic position in this region in a "Resources War" perspective. In this context, for the most countries, mainly by a question of defence rather than by a question of dominance in the resources war, the renewable energies constitute the best alternative. However, in order to do so, institutional innovation will be crucial. On the other hand, even if the great radical innovations happen at the more developed countries, other important developments, but of smaller impact, can happen at countries of smaller development. In other words, the development countries can have an important paper in the investigation / diffusion of the renewable alternative energies, due to the financial and social problems of nuclear energy, in spite of the possibility of never be despised as an alternative. In this sense, it is believable that we are moving toward alternative energies and, consequently, through the substitution dynamics, it is possible not only to reduce the carbonic intensity, as well as the absolute emission of carbon around 20402060 .

\section{Acknowledgement}

The authors of this study would like to thank everyone involved in Delphi panel.

\section{References}

[1] MATIAS, J. C. O. - "Construção de Cenários Futuros para as Fontes de Energia Primária", Doctoral Dissertation, University of Beira Interior, Covilhã, 2003 (in Portuguese).

[2] AYRES, R. U. - "Technological transformations and long waves - Part I", Technological Forecasting and Social Change, Volume 37, $\mathrm{n}^{\circ} 1$, March 1990, pp. 1-37.

[3] AYRES, R. U. - "Technological transformations and long waves - Part II", Technological Forecasting and Social Change, Volume 37, $\mathrm{n}^{\circ} 2$, April 1990, pp. 111-137.

[4] PODOBNIK, B. - "Toward a sustainable energy regime: A long-wave interpretation of global energy shifts", Technological Forecasting and Social Change, 62, 1999, pp. 155-172.

[5] HAMMOND, G. P. - "Energy, Environment and sustainable development: A UK perspective", Trans IChmE, Volume 78, Part B, July 2000, pp. 304-323.

[6] DOOLEY, J. J. - "Unintended consequences: Energy R\&D in Deregulated Market", Energy Policy, June 1998, pp. 547-555.

[7] DEVEZAS, T., C. and CORREDINE, J. T. - "The biological determinants of long wave behaviour in socio-economic growth and development", Technological Forecasting and Social Change, 68, 2001, pp. 1-57. 